submit to it, to be guided by it, in those areas where basic political decisions are made" (p. 181).

The authors' task is well executed, for one rarely encounters a more satisfying book written by as many as four authors. If any regrets are to be expressed, it is that the authors have limited themselves much too narrowly, both conceptually and empirically. The material they present begs for linkage to some of the central questions posed by classical social theorists. Tocqueville, for example, considered public opinion to be a replacement for traditional authority. According to this view, given the absence of genuine intermediate associations between the individual and the state, as in the case with socialist societies, public opinion operates for the benefit of centralized, tyranny-prone authority. There seems to be a need to reconcile Tocqueville's view (and similar views of other classical writers) with the contributors' implicit assumption that the full-fledged operation of public opinion would somehow work in opposition to the tyranny of the party.

Moreover, by excluding Bulgaria, the authors lost an opportunity to examine a unique case of survey research in a highly bureaucratized stage of development. Bulgarian sociology is primarily a research discipline with direct state support that does not have to be filtered either through the university or the Academy of Sciences. Nationwide survey results are channeled directly to the appropriate organs of the party and the government, and seem to be even more secret than those of other socialist countries. One can argue that future public opinion polling and sociology in European socialist systems is more likely to resemble that of Bulgaria than the other way around.

Alex Simirenko

The Pennsylvania State University

\title{
JAHRBUCH DER WIRTSCHAFT OSTEUROPAS. Edited by Hans Raupach. Yearbook of East-European Economics, vol. 6. Veröffentlichung des Osteuropa- Instituts München. Munich and Vienna: Günter Olzog Verlag, 1975. 487 pp. Tables.
}

The first two sections of this book contain fifteen essays on East European economics by Western and East European contributors. With few exceptions these essays are disappointing, either yielding indifferent answers to interesting questions or addressing questions of dubious importance. The blame for this low quality can be laid, to a great extent, at the feet of the editors: the book contains ample evidence of their indifference toward editing. Thus, none of the English-speaking editors saw fit to render the editors' preface into proper English. Similarly, the articles by East European contributors were published in the form in which they were received. While I admire the ability of these authors to write scientific papers in a language other than their native tongue, their ideas would have been much more comprehensible and better received had the editors undertaken to improve the grammar and the technical vocabulary of these papers. In all fairness it must be reported that the editors did not discriminate in their indifference; one of them clearly failed to proofread his own contribution.

Amidst all this, two contributions worthy of note are those by Jozef van Brabant and John P. Farrell. Van Brabant examines the pattern of Polish foreign trade in order to determine the way in which unplanned trade transactions are accommodated in Poland's trade with market and planned economies. He makes skillful use of limited data and scrupulously points out the potential shortcomings of his findings. Farrell examines the operations of the Polish National Bank from 1950 to 1970. Although 
his use of a "model" is somewhat forced, he does present a useful case study of the problens faced by bankers in a planned economy.

The final section of the book contains economic statistics of a rather limited nature for each of the East European countries.

Josef C. BRADA

Arizona State University

NATIONALITY GROUP SURVIVAL IN MULTI-ETHNIC STATES: SHIFTING SUPPORT PATTERNS IN THE SOVIET BALTIC REGION. Edited by Edward Allworth. Published in cooperation with the Program on Soviet Nationality Problems, Columbia University. New York and London: Praeger Publishers, 1977. xvi, 302 pp. Tables.

Focusing on Lithuania, Latvia, and Estonia, this collection of essays is concerned with determining what factors are important for the survival of nationality groups. especially in a modernizing, multinational, and authoritarian society. The individual studies explore various aspects of the problem, including: the possible defenses of groups, the roots of nationality differences, the significance of culture and religion, the interests of indigenous historians, the importance of national leadership in politics and economics, social distance between groups, and the special problems of Baltic Jews. In addition to non-Soviet sources, the authors rely on original Soviet material and on translations of Soviet material, including samizdat publications. Some of these are included in the appendixes, and a general bibliography is also provided.

In his introductory essay, Professor Allworth discusses the many support factors available to groups, and states that a group is most likely to survive if it learns to shift these support patterns in response to new situations. The remaining articles illustrate well how ethnic groups in the Baltic area have adapted to modernizing pressures. Despite official objections, historians from this area often write about Baltic and international, rather than Soviet, subjects. Economic progress has increased regional pride and desire for more local control. Moscow's efforts to encourage "internationalization" have revived interest in regional language and customs and have even led to overt dissent. Both Russians and Jews are made to feel somewhat unwelcome. Although current leaders, even those who are indigenous, are often Moscow-oriented, changes in party membership suggest that the future leadership could be more representative. Thus, the Baltic groups have been able to shift from an identity which is based on the past and on a largely rural culture to one which emphasizes education and economic achievements. The groups have responded in different ways: the strong historical and religious heritage of the Lithuanians sometimes leads to hostile demonstrations, while the Estonian expression is largely cultural, and the Latvian response is somewhat weakened by historical, cultural, and regional splits. Jewish dissatisfaction can be seen in demonstrations, petitions, and emigration. The results of the studies suggest that, thus far, ethnic identity has been increased by Soviet policies designed to decrease it.

These studies seek to analyze from a distance such elusive concepts as national identity, national attitude, and national satisfaction or dissatisfaction. The conclusions are necessarily based on inferences from available sources or on interviews with emigrants and must be used with care. Even so, the collection constitutes a valuable addition to the understanding of ethnic processes in the Soviet Union and in the world.

Catharine V. Ewing Phillips University 